\title{
Boosting the in situ encapsulation of proteins with MIL-100(Fe): the role of strong Lewis acid centers
}

Jesús Cases Díaz, Mónica Giménez Marqués*

\author{
J. Cases Díaz, Dr. M. Giménez Marqués \\ Instituto de Ciencia Molecular (ICMol) \\ Universidad de Valencia \\ C/ Catedrático José Beltrán 2, 46980, Spain \\ E-mail: monica.gimenez-marques@uv.
}

Keywords: Metal-Organic Frameworks, in situ protein encapsulation, biocomposites, triggered delivery

Encapsulation of biomolecules using Metal-Organic Frameworks (MOFs) to form stable biocomposites has been demonstrated a valuable strategy for their preservation and controlled release, which has been however restricted to specific electrostatic surface conditions. We present a general in situ strategy that promotes the spontaneous MOF growth onto a broad variety of proteins, for the first time, regardless of their surface nature. We demonstrate that MOFs based on cations exhibiting considerable inherent acidity such as MIL-100(Fe) enable biomolecule encapsulation, including alkaline proteins previously inaccesible by the welldeveloped in situ encapsulation with azolate-based MOFs. In particular, MIL-100(Fe) scaffold permits effective encapsulation of proteins with very distinct surface nature, retaining their activity and allowing triggered release under biocompatible conditions. This general strategy will enable an ample use of biomolecules in desired biolotechnological applications.

\section{Introduction}

Enzymes are catalytic proteins extraordinarily valuable for chemical production due to their unique specificity, low by-product generation and the number of reaction types in which are efficient ${ }^{[1]}$. However, their structural instability limits their operational capacity to exclusive mild conditions ${ }^{[2]}$. Certainly, the implementation of enzymes, including production of biochemicals ${ }^{[3,4]}$, and biofuels ${ }^{[5]}$, biosensing ${ }^{[6,7]}$, bioremediation purposes $^{[8]}$, and as therapeutic agents ${ }^{[9]}$, requires their immobilization on a support to increase their stability, enable long-term storage and facilitate their recovery ${ }^{[10]}$. 
A broad variety of materials have been studied as supports for enzyme immobilization, including organic and inorganic systems such as (bio)polymers, ${ }^{[1,12]}$ carbon materials $^{[13]}$, vesicles $^{[14,15]}$, sol-gel materials ${ }^{[16]}$, and mesoporous silica ${ }^{[17]}$. More recently, hybrid crystalline porous materials known as Metal-Organic Frameworks (MOFs) have also been explored as a porous support for enzymes ${ }^{[18-21]}$. Constituted by the assembly of metal nodes with organic linkers, MOFs are characterized by their chemical versatility resulting in unique structures with modulable functional pores ${ }^{[22-25]}$ that exhibit a multitude of applications for advancement of technologies such as gas storage/separation ${ }^{[26-28]}$, catalysis $^{[29]}$, electronics ${ }^{[30]}$, water harvesting and remediation $^{[31,32]}$, and in the biomedical field ${ }^{[33-36]}$.

For the immobilization of enzymes using MOFs, different strategies have been considered $^{[37,38]}$, including surface adsorption ${ }^{[39,40]}$, conjugation ${ }^{[41]}$, pore encapsulation ${ }^{[19,42]}$ or in situ synthesis ${ }^{[21,43]}$. In particular, the in situ approach consists in the entrapment of the enzyme provided the nucleation and growth of the MOF on the surface of the biomolecule. This strategy presents some advantages over the rest, which are i) a high encapsulation efficiency that maintains the protein entrapped with negligible leaching; ii) the use of reaction conditions that retain the integrity of the protein and iii) the possibility of encapsulating biomolecules regardless of their size or shape (i.e. surpassing the volume requirement imposed by pore infiltration), therefore minimizing undesired translocation effects that may render loss of activity during the encapsulation process $^{[37,44]}$. Considering these advantages, the most critical aspect is that the in situ encapsulation is limited to MOF structures that can be synthesized under specific mild conditions suitable to preserve the fragile enzyme nature. For this reason, most of studies related to in situ formation of MOF/enzyme composites refer to the use of ZIFs (Zeolitic Imidazolate Frameworks), in particular to the amenably synthesized $\mathrm{Zn}$ derivative known as ZIF-8.

To date, the successful use of ZIF-8 as a protective agent has been described for a large variety of biomolecules ${ }^{[21,45,46]}$, serving at the basis to reveal the intrinsic electrostatic mechanism for the in situ MOF growth, which is triggered by the preferential binding of $\mathrm{Zn}^{2+}$ ions to the biomolecule surface ${ }^{[37,47]}$. The simultaneously coexistence of both positive and negative charges onto the proteins surface governs the interaction with the MOF constituents and determines their further formation. Essentially, $\mathrm{Zn}^{2+}$ leads to a favoured coordination to proteins exhibiting carboxylate-rich surfaces (i.e. low isoelectric point ( $\mathrm{pI}$ ) proteins), whereas poorly coordinates to biomolecules with positively charged surfaces (i.e. high pI proteins) ${ }^{[37,48]}$. Therefore, proteins characterized 
by high $\mathrm{pI}$ have shown to inhibit the formation of ZIF-8, either preventing the formation of the composite ${ }^{[47,49]}$ or resulting in a delayed composite formation associated with significative activity loss due to the high $\mathrm{pH}$ reached on the media ${ }^{[49]}$.

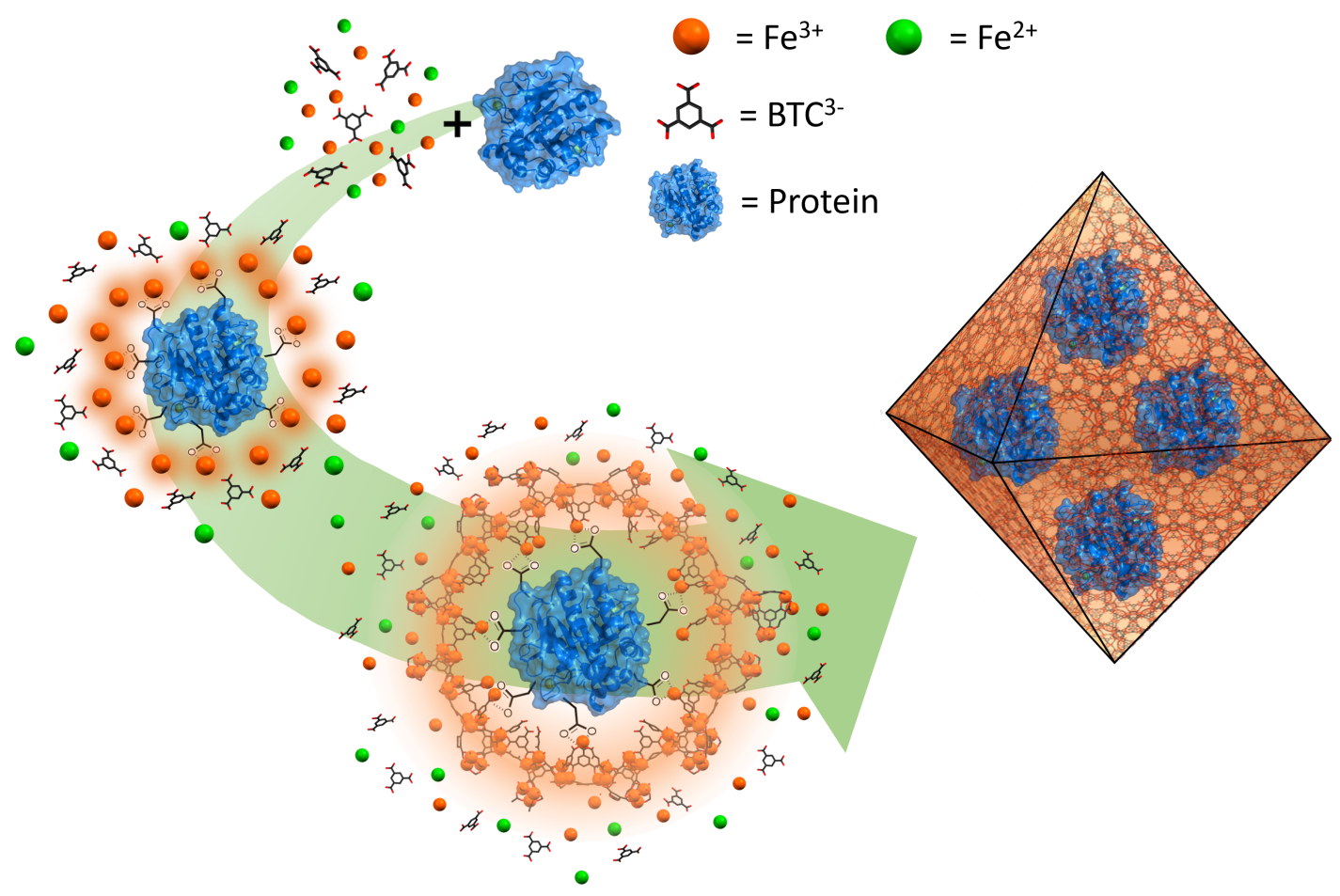

Figure 1: Schematic representation of in situ protein encapsulation into MIL-100(Fe).

This hampered encapsulation in alkaline proteins has been recently solved by surface functionalization (e.g. succinylation ${ }^{[47]}$ ) or modification (e.g. PVP wrapping ${ }^{[20,49]}$ ), which could in some cases compromise the enzyme activity. At this point, it is essential to develop in situ growth strategies involving new MOFs that effectively promote the encapsulation of bioentities regardless of their size, shape and surface nature.

We propose a general enzyme encapsulation that relies in the in situ formation of MOFs based on cations exhibiting considerable inherent acidity, such as $\mathrm{Fe}^{3+} .{ }^{[50,51]}$

In this work, we have particularly selected the mesoporous $\mathrm{Fe}^{3+}$ trimesate crystalline MIL-100(Fe) $\mathrm{MOF}^{[52]}$, based on its unique characteristics, including i) a suitable composition based on $\mathrm{Fe}^{3+}$ cations, which display the optimal Lewis acidity for establishing effective interactions with the protein surface; ii) a feasible synthesis at specific biocompatible conditions; and iii) an optimal thermal and chemical stability that provide protein protection while permitting targeted degradation under physiological conditions. In addition, in an attempt to evaluate the broadness of the in situ 
encapsulation using MIL-100(Fe), we have selected a group of model proteins exhibiting very different isoelectric points $(5<\mathrm{pI}<11)$, demonstrating the exceptional capacity of the material to form in all cases. We demonstrate that the stronger interactions established between the $\mathrm{Fe}^{3+}$ cation and the bioentity surface fosters the formation of a MOF shell onto a broader variety of proteins under physiological conditions, including those currently inaccessible by the azolate-MOF route.

\section{Results and Discussion}

\subsection{General in situ encapsulation of proteins by MIL-100(Fe)}

A general in situ strategy to form protein@MIL-100(Fe) biocomposites is presented. (Figure 1). The encapsulation relies on the triggered overgrowth of the mesoporous iron(III) trimesate MOF known as MIL-100(Fe) in the presence of a variety of proteins exhibiting very different isoelectric points $(5<\mathrm{pI}<11)$, including bovine serum albumin (BSA, pI 5.10 $0^{[53]}$ ), equine myoglobin $\left(\mathrm{Mb}\right.$, pI $\left.7.20^{[54]}\right)$, subtilisin Carlsberg (SubC, pI 9.40 ${ }^{[55]}$ ) and bovine cytochrome C (CytC, pI 10.25 $5^{[56]}$ ). In a typical procedure, a $20 \mathrm{~mL}$ aqueous solution of iron(III) chloride $(20 \mathrm{mM})$ was slowly added to a $20 \mathrm{~mL}$ buffered aqueous solution (Tris $100 \mathrm{mM}, \mathrm{pH} 7,5$ ) containing a mixture of benzene 1,3,5-tricarboxylic acid (BTC) ligand (20 mM), iron(II) chloride (20 mM) and 4 mg of each protein. A control synthesis in the absence of protein was similarly performed to obtain MIL-100(Fe). To gain further insights into the in situ reaction a family of SubC@MIL-100(Fe) biocomposites with different protein loadings was synthesized following the same general procedure but adding a particular amount of SubC (4, 20 and $40 \mathrm{mg}$, respectively for biocomposites SubC@MIL-100(Fe) 1, 2 and 3. This model basic protease was intentionally selected provided its high pI, an electrostatic factor that is known to disfavor the biomineralization process in case of ZIF-8 being used as exoskeleton.

In all cases, biocomposite formation was immediately initiated upon addition of iron(III) chloride solution and detected by the formation of suspended orange particles. Reaction completion was achieved in $1 \mathrm{~h}$, reaching a final $\mathrm{pH}$ around 4,5 distinctive of MIL$100(\mathrm{Fe})$ material. All biocomposites and the control protein-free material were collected by centrifugation and thoroughly washed with water. Part of each biocomposite was stored in water, and the rest was dried on air at room temperature for further characterisation. To ascertain the inner location of the encapsulated proteins and 
discharge the presence of surface bound proteins, biocomposites were washed with surfactant prior examination.
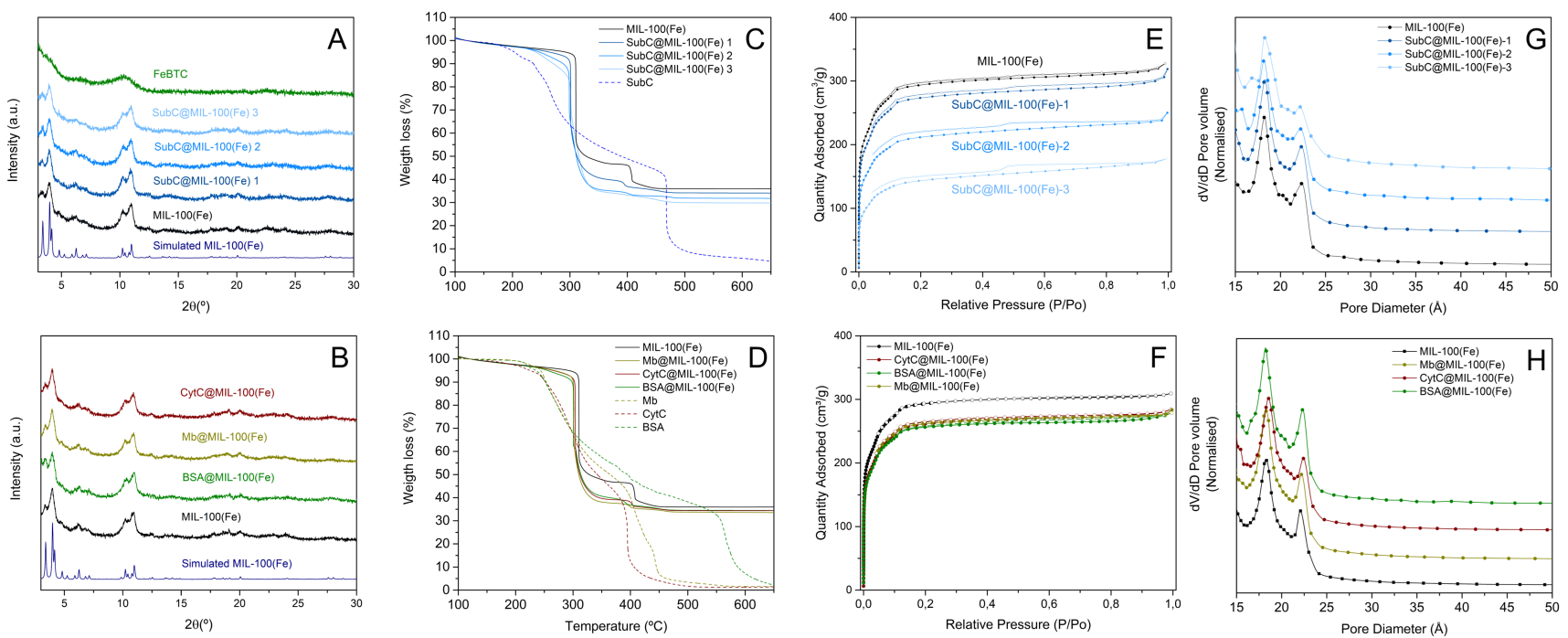

Figure 2: Physico-chemical characterizations of MIL-100(Fe), free SubC and the different protein@MIL-100(Fe) composites. (A,B) XRD patterns. (C,D) TGA profiles normalized after evacuation of volatiles (at $100^{\circ} \mathrm{C}$ ). (E,F) $\mathrm{N} 2$ adsorption (open circles) and desorption (filled circles) isotherms for the SubC@MIL-100(Fe) composites with different loading (E) and BSA@MIL-100(Fe), Mb@MIL-100(Fe) and CytC@MIL$100(\mathrm{Fe})$ biocomposites (F) measured at $77 \mathrm{~K}$. (G,H) Pore size distribution calculated from the adsorption curves.

First evidence of biocomposite formation was supported by X-ray powder diffraction (XRPD) that confirmed in all cases an optimal phase-purity and the MIL-100 topology (Figure 2A and 2B). It is worth mentioning that all biocomposites and MIL-100(Fe) control present a remarkable crystallinity despite using biocompatible synthetic conditions which has been achieved by adding $\mathrm{Fe}^{2+}$ during synthesis. The addition of $\mathrm{Fe}^{2+}$ with a reduced Lewis acid character promotes coordinative reversibility, therefore acting as a coordination modulator that improves the crystallinity ${ }^{[57,58]}$. Indeed, the semiamorphous Fe-BTC material (commercially referred as Basolite F-300) is obtained in the absence of $\mathrm{Fe}^{2+}$ (Figure $2 \mathrm{~A}$ and S1), as previously described ${ }^{[59]}$.

The loading capacity in the different biocomposites was determined by examining the differences in the concentration of enzymes in the supernatant before and after encapsulation following a standard BCA method (see experimental section). Table 1 summarizes the obtained protein content, which in case of BSA@MIL-100(Fe), 
Mb@MIL-100(Fe),SubC@MIL-100-1 and CytC@MIL-100(Fe) resulted $c a .4 \%$ $\mathrm{w} / \mathrm{w}$.

Table 1. Summary of the enzyme-free MIL-100(Fe) material and the different biocomposites obtained with BSA, Mb, SubC and CytC indicating enzyme contents, encapsulation efficiencies and particle size measured as hydrodynamic diameter.

\begin{tabular}{llll}
\hline Sample & $\begin{array}{l}\text { Protein } \\
\text { content }(\mathbf{\%})\end{array}$ & $\begin{array}{l}\text { Encapsulation efficiency } \\
\mathbf{( \% )}\end{array}$ & $\begin{array}{l}\text { Size } \\
\text { (nm) }\end{array}$ \\
\hline MIL-100(Fe) & - & - & $72,8 \pm 1,7$ \\
\hline BSA@MI-100(Fe) & $4,2 \pm 0,1$ & $100,0 \pm 0,3$ & $84,4 \pm 0,3$ \\
\hline Mb@MIL-100(Fe) & $4,3 \pm 0,1$ & $99,8 \pm 0,4$ & $84,1 \pm 0,4$ \\
\hline SubC@MIL-100(Fe)-1 & $4,4 \pm 0,0$ & $100,0 \pm 1,5$ & $71,9 \pm 3,1$ \\
\hline SubC@MIL-100(Fe)-2 & $16,2 \pm 0,2$ & $99,1 \pm 0,1$ & $92,9 \pm 8,7$ \\
\hline SubC@MIL-100(Fe)-3 & $30,5 \pm 0,3$ & $98,6 \pm 0,2$ & $116,6 \pm 3,4$ \\
\hline CytC@MIL-100(Fe) & $4,2 \pm 0,1$ & $98,8 \pm 3,3$ & $80,5 \pm 3,3$ \\
\hline
\end{tabular}

In the case of the composites SubC@MIL-100(Fe)-2 and 3, increasing loading values of $16,2 \pm 0,2$ and $30,5 \pm 0,3 \%$ were respectively obtained. In all cases high loading efficiencies (between 100-98\%) were obtained, with negligible presence of enzyme surface bounded (Table 1). Analysis of the particle size of the obtained biocomposites was determined by Dynamic Light Scattering (DLS). Hydrodynamic values of $c a .80$ $\mathrm{nm}$ were obtained for biocomposites containing BSA, Mb and CytC, which are slightly larger than the $c a .73 \mathrm{~nm}$ obtained for SubC@MIL-100(Fe)-1 and MIL-100(Fe) materials. Increasing mean size distribution values of $93 \pm 9$ and $117 \pm 3 \mathrm{~nm}$ were respectively obtained for particles SubC@MIL-100(Fe)-2 and 3 with larger SubC loadings (see Table 1 and Table S1 $\dagger$ ). Chemical composition was ascertained by means of Attenuated Total Reflectance Fourier Transform Infrared (ATR-FTIR) and thermal gravimetric analysis (TGA). Essentially, all IR spectra exhibit similar bands characteristic of MIL-100(Fe) structure, whereas the most representative bands of the proteins appear occluded (Figure S2 and S3). Nevertheless, increases on the 
transmittance could be observed in the amide bands corresponding to the protein. TGA profiles of the biocomposites as compared to the control MIL-100(Fe) and free proteins are represented in Figure 2C and 2D as normalized profiles after evacuation of volatiles (at $100{ }^{\circ} \mathrm{C}$ ). All biocomposites display characteristics weight losses between 200-300 ${ }^{\circ} \mathrm{C}$ attributed to the decomposition of the encapsulated protein (Figure $\mathbf{S 4}$ and Tables S2-S3), affording an estimated content of $c a$. 4, 17 and 25\%, respectively for SubC@MIL-100(Fe) 1, 2 and 3. In addition, BSA@MIL-100(Fe), Mb@MIL-100(Fe) and CytC@MIL-100(Fe) yield protein contents ranging between 4 to 6\%. These results are in agreement with the loading calculated by BCA method (Tables 1 and S4).

The effect on the MOF sorption capacity after enzyme encapsulation was evaluated by $\mathrm{N}_{2}$ sorption studies (Figure 2E). Characteristic type I isotherms of MIL-100(Fe) structure $^{[60]}$ were recorded for all the materials. Calculated Brunauer-Emmett-Teller $(\mathrm{BET})^{[61]}$ surface area of control MIL-100(Fe) resulted in significantly lower value as compared to the previously reported nanostructured MIL-100(Fe) material (1077 vs $1450 \mathrm{~m}^{2} \cdot \mathrm{g}^{-1}$, respectively $\left.{ }^{[62]}\right)$. This lower porosity may be attributed to some extent to the biocompatible synthetic conditions, although it may essentially be related to the mild activation conditions used $\left(100{ }^{\circ} \mathrm{C}\right.$ for $\left.2 \mathrm{~h}\right)$ prior surface analysis to prevent enzyme degradation. Indeed, stronger activation conditions $\left(150{ }^{\circ} \mathrm{C}\right.$ for $\left.6 \mathrm{~h}\right)$ substantially increased this sorption capacity. Then, the estimated BET areas in the SubC biocomposites 1, 2, and 3 subsequently decreased to 1004,773 and $522 \mathrm{~m}^{2} \cdot \mathrm{g}^{-1}$, as expected for increasing SubC loadings. The composites BSA@MIL-100(Fe), Mb@MIL-100(Fe) and CytC@MIL-100(Fe) showed slightly reduced porosity (respectively 942, 958 and $947 \mathrm{~m}^{2} \cdot \mathrm{g}^{-1}$ ) as compared to the enzyme-free MIL-100(Fe) $\left(1077 \mathrm{~m}^{2} / \mathrm{g}\right)$ (Figure 2 F). The pore size distribution was not significantly affected by the presence of proteins (Figure 2G and 2H), except in the highest loading of SubC, where a massive presence of enzyme leads to the appearance of additional narrower pores.

In a control study, we investigated the immobilization of this group of enzymes using ZIF-8 under similar synthetic conditions. As a result, only BSA could be efficiently immobilized, in good agreement with the reported results ${ }^{[63,64]}$. This experimental data confirms the unique MIL-100(Fe) capability to encapsulate, by in situ crystallization, a range of proteins exhibiting very distinct surface electrostatic properties ( $\mathrm{pI}$ and zeta potential). This is particularly interesting in case of the in situ encapsulation of basic proteins (SubC and CytC), a process that is hampered in the archetypal ZIF-8 under standard protein conditions. 


\subsection{Electrostatic characterization at the protein-MOF interface}

As outlined, controlling the electrostatic interactions at the protein-MOF interface determines the extent of biocomposite formation. Protein-MOF interactions, however, have been considered from the protein's surface chemistry, disregarding the key role that metallic MOF precursors may play in inducing crystallization. In this sense, our experiments highlight that the superior MIL-100(Fe) encapsulating performance relies on the remarkable $\mathrm{Fe}^{3+}$ affinity towards the surface proteins. This enhanced interaction may lead to a significant concentration of this cation on the protein surface acting as seeding for crystallization.

To evaluate the extent of this $\mathrm{Fe}^{3+}$-protein affinity and validate its role on the in situ crystallization, we analysed the electrostatic changes of the different protein surfaces under reaction conditions. For this, we first evaluated the calculated surface potential (Figure 3A) and the theoretical pI of each protein as compared to the experimental zeta potential in water (Figure 3B). A considerably large range of zeta potential values were registered in water (from -17.5 to $17.0 \mathrm{mV}$ ) (Figure $3 \mathrm{~B}$ ) which are in agreement with the calculations (surface potential and $\mathrm{pI}$ ) for each protein studied.
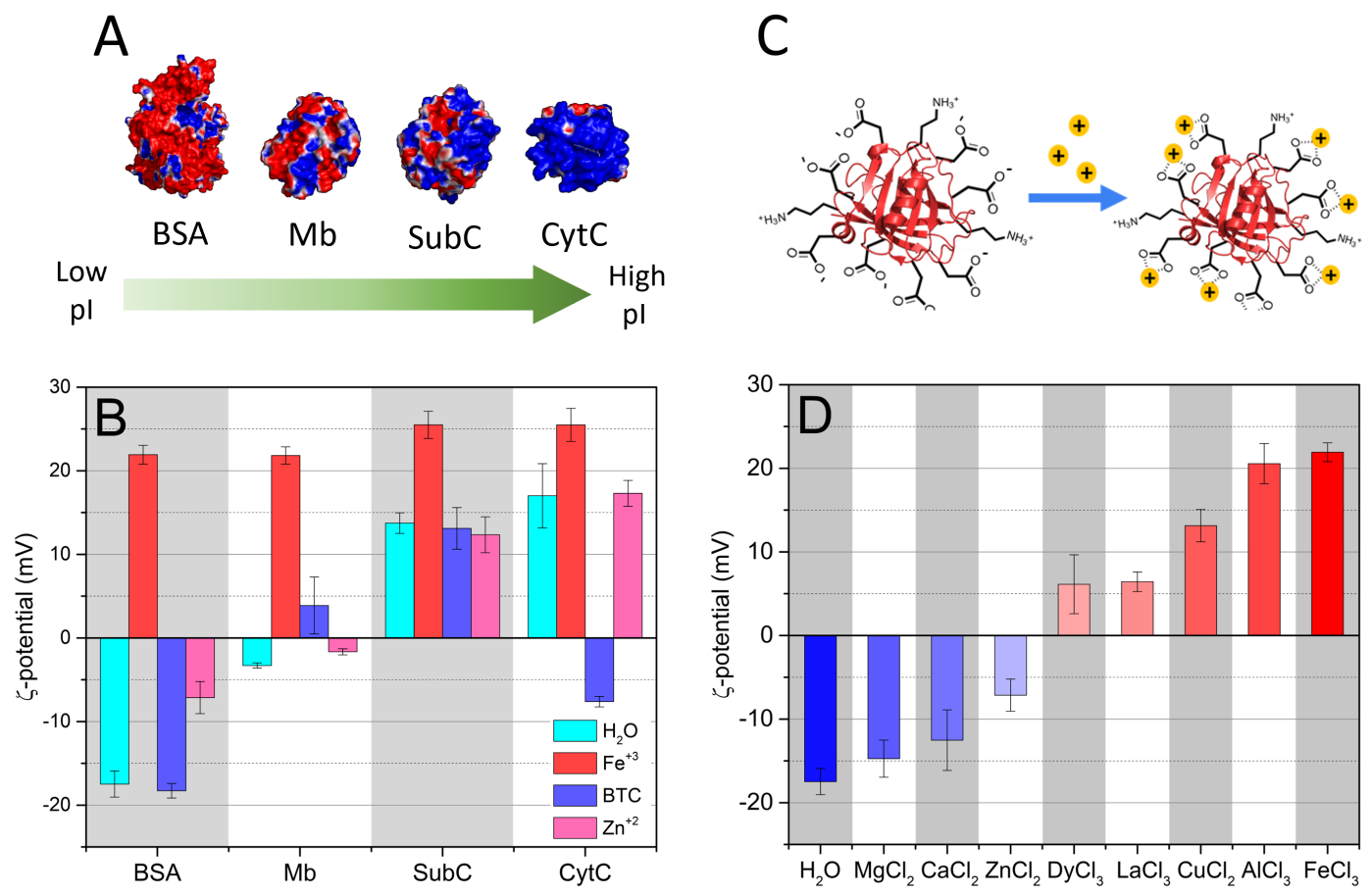

Figure 3: (A) Representation of the electrostatic surface potentials of BSA, Mb, SubC and $\mathrm{CytC}$ proteins. The surface potential representation has charge levels from -12.85 $\mathrm{mV}$ (red) to $+12.85 \mathrm{mV}$ (blue). (B) Zeta potential of these proteins measured in presence 
of different ions at $\mathrm{pH} 5,5$. (C) Schematic representation of the adsorption of metal ions or metal hydroxides complexes to protein surface. (D) Zeta potential of BSA solutions incubated in different metal ions at $\mathrm{pH}$ 5,5.

Then, zeta potential of the proteins under investigation was measured after incubation with a $0.2 \mathrm{mM}$ BTC ligand precursor and $0.2 \mathrm{mM}$ of either $\mathrm{Fe}^{3+}$ or $\mathrm{Zn}^{2+}$ metallic precursors (Figure 3B and Table S5). Figure 3B reveals a drastic increase in the Zeta potential upon exposure to $\mathrm{Fe}^{3+}$ for the proteins with low pI, reaching inversion from 17.5 to $21.9 \mathrm{mV}$ in BSA and from -3.3 to $21.8 \mathrm{mV}$ in $\mathrm{Mb}$. A significantly reduced effect was observed upon exposure of these proteins to $\mathrm{Zn}^{2+}$, obtaining only an increase of the zeta potential in BSA from -17.5 to $-7.1 \mathrm{mV}$. In case of proteins with high $\mathrm{pI}$ exposed to $\mathrm{Fe}^{3+}$, an important increase of the zeta potential was measured from 13.7 and $17.0 \mathrm{mV}$ to $25.5 \mathrm{mV}$, respectively for SubC and CytC. The positive zeta potential displayed by these proteins in aqueous solutions hampers in this case a charge inversion. No significant changes were observed upon immersion of these alkaline proteins with $\mathrm{Zn}^{2+}$. Altogether, these results indicate that strong Lewis acid cations like $\mathrm{Fe}^{3+}$, effectively interact with protein surfaces over a large range of $\mathrm{pI}$, while weak Lewis acid cations like $\mathrm{Zn}^{2+}$ only interact effectively with low pI proteins. In addition, BTC ligand appears to have no effect on the zeta potential, except on the case of $\mathrm{CytC}$, where a charge inversion from 17.0 to $-7.6 \mathrm{mV}$ occurs, indicating an effective interaction between proteins with extreme positive charges and the BTC carboxylic groups. These findings validate our straightforward in situ approach using MIL-100(Fe) as encapsulating MOF and are consistent with previous studies establishing that the effective/poor accumulation of the cationic metal precursor at the protein surface triggers/hinders MOF biomineralisation.

Once established the major directing role of the metallic MOF precursor for in situ formation, we wanted to gain more information by studying the effect that different multivalent cations provoke onto the surface of a model protein (Figure 3C). For this, we measured the surface electrostatic potential changes of the model BSA protein upon exposure to divalent $\left(\mathrm{Mg}^{2+}, \mathrm{Ca}^{2+}, \mathrm{Zn}^{2+}\right.$ and $\left.\mathrm{Cu}^{2+}\right)$ and trivalent $\left(\mathrm{Dy}^{3+}, \mathrm{La}^{3+}, \mathrm{Al}^{3+}\right.$ and $\mathrm{Fe}^{3+}$ ) cations. As depicted in Figure 2D, trivalent cations along with $\mathrm{Cu}^{2+}$, leaded to drastic changes including inversion of the zeta potential values, in agreement with reported results ${ }^{[65-67]}$. Indeed, exposure to $\mathrm{Fe}^{3+}$ resulted the most extreme situation and provoked a zeta potential increase of $c a .40 \mathrm{mV}$. However, in case of the divalent cations a minor shifting of the zeta potentials ranging between $3-10 \mathrm{mV}$ was measured. This 
analysis denotes the superior capacity of $\mathrm{Fe}^{3+}$ to accumulate at the BSA surface, as compared to other cations, thus positioning Fe-based MOFs as ideal candidates for the in situ encapsulation of biomolecules.

\subsection{Release of proteins and activity}

Kinetics of enzyme release were conducted in phosphate buffer solution (PBS) at pH 7,4 and at room temperature (RT) in two different concentrations, 10 and $100 \mathrm{mM}$ (see experimental section). These phosphate containing solutions have been previously investigated for the progressive degradation of MIL-100(Fe) as a result of the established competition between carboxylate and phosphate complexant ligands. This MOF degradation occurs to some extent until formation of an iron-phosphate shell around an intact core appears ${ }^{[68]}$ (Figure 4A). Enzyme release was monitored by BCA quantification method and calculated respect to the amount of enzyme loaded (Figure 4B). SubC loaded biocomposites incubated with PBS at $100 \mathrm{mM}$ exhibited a first smooth release reaching in all cases $35.9 \pm 2.0 \%$ of enzyme liberated after $4 \mathrm{~h}$. This profile is followed by a slower continuous delivery, resulting in significant amounts of the enzyme, $54.7 \pm 1.6,42.8 \pm 2.2$, and $45.0 \pm 0.5 \%$, released respectively from biocomposites 1, 2 and 3 after $24 \mathrm{~h}$. Kinetics of release in $10 \mathrm{mM}$ PBS (Figure S5) resulted in an important reduction of the enzyme release $(24.3 \pm 4.4,30.3 \pm$ 0.6 and $25.6 \pm 0.6 \%$, respectively) after $24 \mathrm{~h}$.

To establish the relation between the kinetics of enzyme liberation and the degradation of MIL-100(Fe), we monitored the release of the constituting organic ligand, BTC, under the same conditions (Figure 4B and S5). Degradations conducted under $100 \mathrm{mM}$ PBS solutions afforded $47.5 \pm 1.9 \%$ of the BTC ligand being released from MIL-100(Fe) and $50.2 \pm 0.6,47.3 \pm 4.5$, and $53.9 \pm 2.2 \%$ of BTC delivery respectively for SubC@MIL100(Fe)-1, 2 and 3 after only 4 h. These profiles were saturated after $24 \mathrm{~h}$ reaching important BTC release values of $54.8 \pm 2.3$ for MIL-100(Fe) and $62.7 \pm 5.5,57.9 \pm 5.9$ and $61.3 \pm 3.5, \%$ respectively for SubC@MIL-100(Fe)-1, 2 and 3. Same release assays were carried out with the composites containing BSA, Mb and CytC in PBS $100 \mathrm{mM}$ pH 7,4 (Figure 4C). 

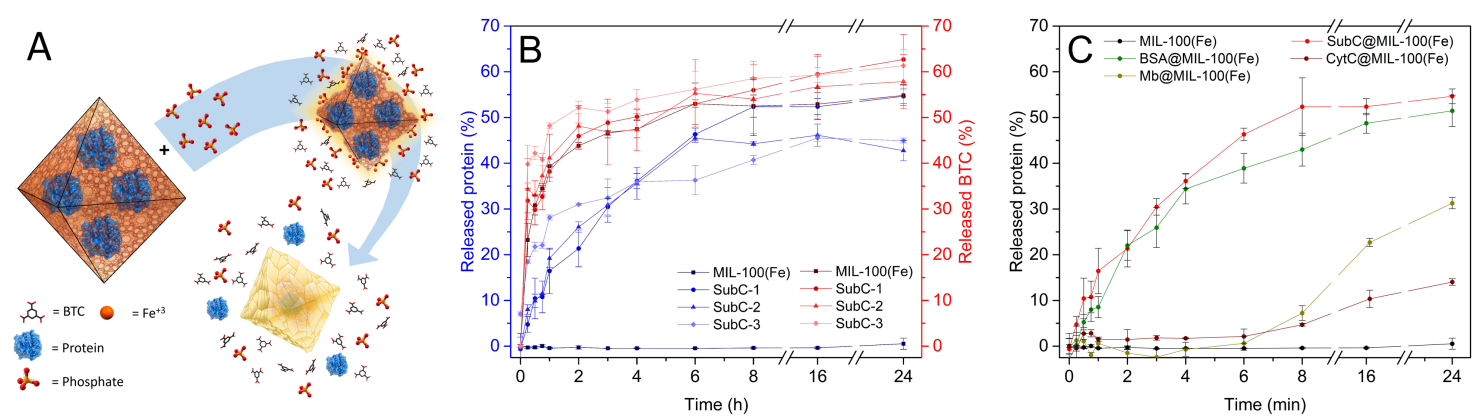

Figure 4: (A) Schematic representation of PBS-triggered biocomposite degradation and subsequent protein release. (B) Release profile of SubC (blue) from SubC@MIL100(Fe) composites in PBS media at $100 \mathrm{mM} \mathrm{pH} \mathrm{7,4} \mathrm{at} \mathrm{RT} \mathrm{and} \mathrm{release} \mathrm{of} \mathrm{BTC} \mathrm{(red).}$ (C) Release of BSA, Mb, SubC and CytC from the corresponding protein@MIL-100(Fe) composites in PBS media at $100 \mathrm{mM}$ pH 7,4 at RT.

BSA exhibits a release profile similar to $\mathrm{SubC}$, while $\mathrm{Mb}$ and $\mathrm{CytC}$ reveal a completely different profile, confirmed by BCA quantification or by absorption of the Soret band. The reason for this different profile is not completely understood, but we hypothesize that the phosphorylation in $\mathrm{CytC}^{[69]}$ and $\mathrm{Mb}^{[70]}$, absent in BSA and SubC, may explain the "lag" phase observed in the release. This phosphate group covalently linked to the protein may bind to iron therefore delaying the degradation and therefore delivery of the encapsulated protein. Then, upon longer PBS exposure (6 and $8 \mathrm{~h}$, respectively in $\mathrm{Mb}$ and CytC) degradation takes place to some extent, provided the competition with free phosphate in the medium. Mb presents a single phosphate group, while CytC presents two of them, which may also explain qualitatively the differences observed. The obtained release profiles are in agreement with the MIL-100(Fe) reported degradation kinetics in PBS considering that less BTC is delivered as a function of time for less concentrated PBS solutions ${ }^{[68,71,72]}$. In addition to the larger PBS concentration used in this work (10 and $100 \mathrm{mM})$, the smaller particle size obtained may also be considered to understand the remarkable MIL-100(Fe) degradation. Altogether, these results suggest that SubC delivery is coupled to the degradation of MIL-100(Fe). 

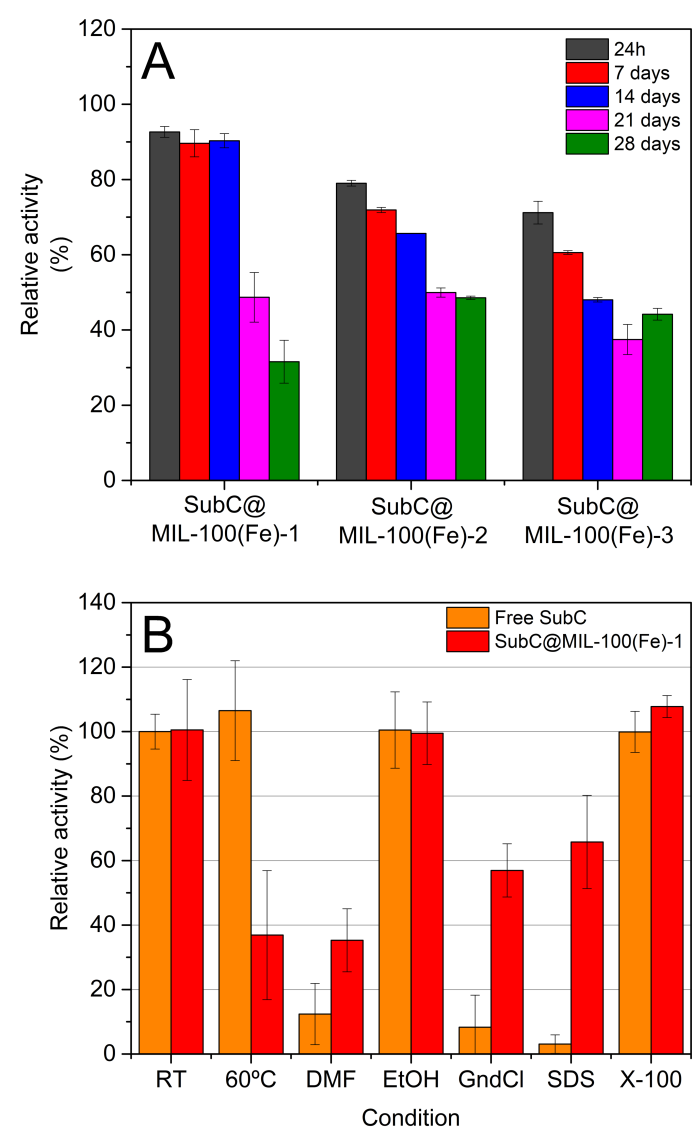

Figure 5: (A) Activity of the delivered SubC from the different SubC@MIL-100(Fe) biocomposites as a function of time when stored in $5 \mathrm{mM} \mathrm{CaCl}_{2}$. (B) Relative $\mathrm{SubC}$ activity after applying different treatments to the free enzyme and the SubC@MIL100(Fe)-1 biocomposite. Abreviations: RT, room temperature; DMF, dimethylformamide; EtOH, ethanol; GndCl, guanidinium chloride; SDS, sodium dodecyl sulphate; X-100, Triton X-100.

Essentially, the primary target of encapsulation is to prevent enzyme from degradation while preserving its activity. For encapsulation and subsequent release was carried out to ascertain that the enzymes conserved their original functionality (Figure 5A). In a first study, a significative loss of activity was observed $24 \mathrm{~h}$ after the synthesis (Figure S8). This prompted us to consider the possibility of enzyme deactivation during encapsulation process. Subtilisins exhibit binding sites for $\mathrm{Ca}^{2+}$, and their activity is dramatically altered by their removal ${ }^{[73,74]}$. We first hypothesized that BTC constituent ligands could easily sequester the $\mathrm{Ca}^{2+}$ therefore disrupting the enzyme activity. To gain insight into this hypothesis, we prevented the $\mathrm{Ca}^{2+}$ loss by two different means, by storing the as-synthesized biocomposite particles in $5 \mathrm{mM} \mathrm{CaCl}_{2}$ solutions, and by performing new synthesis in presence of $20 \mathrm{mM} \mathrm{CaCl}_{2}$. These conditions had no effect 
on the structure of the obtained biocomposite materials as deduced from XRPD analyses (Figure S7). Interestingly, samples stored on $\mathrm{CaCl}_{2}$ at room temperature maintained SubC activity for 2 weeks, while those stored in water experienced significative loss of activity (Figure 5A and S8). In addition, samples synthesized in presence of $20 \mathrm{mM}$ $\mathrm{CaCl}_{2}$ exhibit higher activity than the previously synthesized in its absence (Figure S9). This $\mathrm{Ca}^{2+}$-based activity dependence of the immobilized enzyme confirms our hypothesis that MIL-100(Fe) effectively binds this cation, likely by coordination with carboxyl groups, and removes it from the binding sites of the enzyme. Another important aspect to remark from the activity tests is the effect of the different loadings. It is observed that higher loadings result in lower relative activities and larger loss of activity with time, whereas SubC@MIL-100(Fe)-1 with the lowest loading maintain full activity after two weeks. This observation could be related with an enzyme crowding deactivation, a phenomenon that has been previously detected upon enzyme immobilization and occurs very likely by enzyme-enzyme interactions that lead to conformational changes ${ }^{[75,76]}$. These results highlight the relevance of controlling the enzyme loading in these particular biocomposites, anticipating the benefits of encapsulation with spatial control.

Finally, the shielding effect provided by the MIL-100(Fe) scaffold was evaluated by measuring the enzyme activity after exposure to different conditions as compared to the free enzyme (Figure 5B). A clear conservation of the SubC activity was achieved for the released enzyme after treatment of the biocomposite with DMF, guanidinium chloride and SDS, environments that dramatically affected the activity of the unprotected enzyme (see experimental conditions for details). In case of thermal exposure $\left(60{ }^{\circ} \mathrm{C}\right)$, the shielding effect was not effective, which could in principle be related to a thermally activated $\mathrm{Ca}^{2+}$ sequestration in the particular case of SubC.

\section{Conclusion}

In conclusion, we have demonstrated the possibility to form MOF-based biocomposites by a general in situ mineralization using MIL-100(Fe). We revealed that the direct formation of a MOF-based biocomposite not only relies on the surface electrostatics of the biomolecule but also to the Lewis acid character of the metallic MOF precursor. In particular, we found that strong Lewis acids such as $\mathrm{Fe}^{3+}$ are capable of effectively interacting with the protein surface regardless of its electrostatic surface characteristics (zeta potential and $\mathrm{pI}$ ). This improved $\mathrm{Fe}^{3+}$ accumulation onto the protein surface 
successfully triggers the in situ MIL-100(Fe) crystallization under biocompatible conditions, resulting an effective general encapsulation method capable of incorporating a broad variety of proteins. These results are consistent with previous studies based on zeolitic structures that pointed out the role of $\mathrm{Zn}^{2+}$ in seeding crystallization under specific electrostatic conditions.

Finally, we have shown that MIL-100(Fe) scaffold effectively protects enzymes from severe environments whereas permit controlled delivery under simulated physiological conditions. We anticipate that our findings will enable a general use of MOFs based on strong Lewis acid metal components for the in situ encapsulation of multiple biomolecules, therefore expanding their use in related biotechnological areas.

\section{Experimental Section/Methods}

Particle size measured as hydrodynamic diameter was collected on a Zetasizer Ultra equipment operating at $25{ }^{\circ} \mathrm{C}$, equipped with red $(633 \mathrm{~nm})$ laser and avalanche photodiode detector (Malvern, UK). All aqueous dispersions were prepared by ultrasonication in water bath. Polystyrene cuvettes (DTS0012) were used for size measurement and Folded Capillary Zeta Cell (DTS1070) was used for measurement of zeta potential. Protein samples for zeta potential measurements were prepared by adding $5 \mu \mathrm{L}$ of stock solutions of each protein $(4 \mathrm{mg} / \mathrm{mL})$ to $1,5 \mathrm{~mL}$ of $0,2 \mathrm{mM}$ solutions of each metal salts (pH 5,5). Employing a diffusion barrier preparation, around 100 to 200 $\mu \mathrm{L}$ of these samples were loaded with a needle into the measurement zone of the Folded Capillary Zeta Cell (DTS1070) previously filled with $\mathrm{ddH}_{2} \mathrm{O}$. Electrostatic potentials were calculated using PDB2PQR web service ${ }^{[77]}$ from the PDB files (BSA: 3v03, Mb: 1azi, SubC: $1 \mathrm{c} 31, \mathrm{CytC}: 2 \mathrm{~b} 4 \mathrm{z})^{[78-81]}$ of the corresponding proteins and visualized with PyMOL. UV-vis measurements were done in a UV-VIS-NIR spectrophotometer V-670 (Jasco) using a $1 \mathrm{~mL}$ quartz cuvette with a $1 \mathrm{~cm}$ optical path. A UV-vis microplate spectrophotometer Multiskan Sky (Thermo Scientific) was also employed. FT-IR was performed on an ALPHA II spectrometer (Bruker) in the range $400-4000 \mathrm{~cm}^{-1}$ using the ATR accessory with a diamond window. XRPD patterns were obtained using an Xray diffractometer (PANanalytical Empyrean) with cooper as a radiation source $(\mathrm{Cu}-\mathrm{K} \alpha$ $1,5418 \AA$ ) operating at $40 \mathrm{~mA}$ and $45 \mathrm{kV}$ and equipped with an $\mathrm{X}^{\prime}$ Celerator detector. Measurements were collected on quartz capillaries or in a high throughput screening platform (HTS). TGA profiles were collected using a TGA 550 (TA instruments) at temperatures from 25 to $600^{\circ} \mathrm{C}$ under $\mathrm{N}_{2}$. The heating rate was stablished in high resolution mode $(\mathrm{HR})$, starting by $5^{\circ} \mathrm{C} / \mathrm{min}$ and decelerating when significant weight 
variation is measured. $\mathrm{N}_{2}$ isotherms were measured with a TRISTAR-2 apparatus (Micromeritics) at $77 \mathrm{~K}$. Before the measurement, samples were degassed at $100{ }^{\circ} \mathrm{C}$ for 1 hour in vacuum. Surface area was calculated using the Brunauer-Emmett-Teller $(B E T)^{[61]}$ equation from the adsorption curve. Pore size distribution was calculated with the Broekhoff-De Boer ${ }^{[2,83]}$ : Kruk-Jaroniec-Sayari correction ${ }^{[84]}$, employing the adsorption curve.

Biocompatible synthesis of $M I L-100(\mathrm{Fe})$. A ligand solution containing $0,084 \mathrm{~g}$ of BTC $(0,4 \mathrm{mmol})$ and $0,242 \mathrm{~g}$ of Tris base $(2,0 \mathrm{mmol})$ were dissolved in Mili-Q water adjusting the $\mathrm{pH}$ to 7,5 with diluted hydrochloric acid and the volume was adjusted to $20 \mathrm{~mL}$. After this, the solution was degassed, and $0.080 \mathrm{~g}$ of iron (II) chloride tetrahydrate $(0.4$ mmol) were dissolved. In a separate vial, a solution of $0,108 \mathrm{~g}$ of iron(III) chloride hexahydrate $(0,4 \mathrm{mmol})$ in $10 \mathrm{~mL}$ of Milli-Q water was prepared. Both solutions were degassed by bubbling $\mathrm{N}_{2}$ for 15 minutes. After this, the ligand solution was left under stirring in a closed vessel under $\mathrm{N}_{2}$ stream, and the iron (III) chloride solution was loaded in a syringe. The reaction started by pouring the iron(III) solution with a perfusor (B. Braun, Germany) at a rate of $10 \mathrm{~mL} / \mathrm{h}$ at room temperature. After 1 hour of addition the reaction was completed, and the resulting orange mixture was centrifuged at $8000 \mathrm{rpm}$ for 1 minute. The supernatant was discarded, and the sample was resuspended in MiliQ water and centrifuged again at $8000 \mathrm{rpm}$ for 10 minutes. This washing step was repeated three times. Finally, part of the sample was stored in wet, and the rest was dried on air at room temperature.

Synthesis of Fe-BTC. The synthesis of Fe-BTC was carried out following the same procedure that for MIL-100(Fe) but without adding iron(II) chloride in the synthesis.

Synthesis of protein@MIL-100(Fe) biocomposites. The synthesis of the different protein@MIL-100(Fe) biocomposites followed the same biocompatible procedure developed for MIL-100(Fe) material with addition of the corresponding protein. In case of SubC@MIL-100(Fe) biocomposites, the synthesis was carried in presence of $20 \mathrm{mM}$ $\mathrm{CaCl}_{2}$. Then, 4, 20 and $40 \mathrm{mg}$ of SubC were added to the ligand solution resulting in SubC@MIL-100(Fe) 1, 2 and 3, respectively. In case of BSA@MIL-100(Fe), Mb@MIL-100(Fe) and CytC@MIL-100(Fe), 4 mg of the corresponding proteins were added to the ligand solution. Recovery of the biocomposites was carried out by centrifugation for 1 minute at $8000 \mathrm{rpm}$. After removal of the supernatant the pellet was 
resuspended in Milli-Q water. This washing step was repeated three times. All biocomposites were finally washed with surfactant prior examination. A fraction of the composite was stored wet, while the rest was dried on air at room temperature. Also, some aliquots of SubC@MIL-100(Fe)were stored in 5 mM CaCl 2 .

Protein encapsulation efficiency. The efficiency of the encapsulation was assessed by determining the difference in protein concentration in the supernatant. Aliquots of the supernatant $(1 \mathrm{~mL})$ were recovered by micropipette. Then, $50 \mu \mathrm{L}$ of supernatant was mixed with $1000 \mu \mathrm{L}$ of working reagent solution of BCA protein assay (Thermo Scientific, Pierce BCA Protein Assay Kit). The solution was left for 30 minutes at 37 ${ }^{\circ} \mathrm{C}$. Afterwards, this mixture was analyzed by UV-vis (592 nm). Alternatively, $\mathrm{Mb}$ and CytC could be quantified with UV-vis by absorbance on the Soret band. All the experiments were performed in triplicates. In addition, to determine that the protein was encapsulated and not surface attached, $1 \mathrm{mg}$ of each sample was washed with $1 \mathrm{~mL}$ of a solution of sodium dodecyl sulfate (SDS) $5 \%$ for $30 \mathrm{~min}$ at $60{ }^{\circ} \mathrm{C}$ with orbital shaking at $1500 \mathrm{rpm}$. Then, the samples were centrifugated at 8000 or $10000 \mathrm{rpm}$ and the supernatant was used to measure the protein content as previously described.

Enzyme release and activity assay. Encapsulated enzymes were released from the composite by direct degradation with PBS solution pH 7,4 at 100 and $10 \mathrm{mM}$. $1 \mathrm{mg}$ of sample was suspended in $1 \mathrm{~mL}$ of PBS $100 \mathrm{mM} \mathrm{pH} \mathrm{7,4.} \mathrm{At} \mathrm{regular} \mathrm{time} \mathrm{intervals,}$ samples were taken from the mixture and centrifugated at $8000 \mathrm{rpm}$ for $2 \mathrm{~min}$. Then, supernatant was taken and employed for BTC ligand and protein quantification, and activity assay if proceeded. See ESI $\uparrow$ for details on BTC quantification. Protease activity of the released enzyme was measured spectrophotometrically by the azocasein hydrolysis method ${ }^{[85]}$. Briefly, $150 \mu \mathrm{L}$ of sample was added to $150 \mu \mathrm{L}$ of the corresponding buffer in a $1,5 \mathrm{~mL}$ centrifuge tube. $300 \mu \mathrm{L}$ of $1 \%(\mathrm{w} / \mathrm{v})$ azocasein dissolved in the corresponding buffer was added, and the reaction mixture was incubated at $40{ }^{\circ} \mathrm{C}$ for $10 \mathrm{~min}$ in a dry block heater (ThermoMixer C; Eppendorf). The reaction was terminated by adding $600 \mu \mathrm{L}$ of $10 \%(\mathrm{w} / \mathrm{v})$ trichloroacetic acid (TCA), and the tube was placed on ice for $1 \mathrm{~min}$. This was followed by centrifugation at 13,400 rpm for 2 $\min .800 \mu \mathrm{L}$ of the supernatant was collected and neutralized by adding $200 \mu \mathrm{L}$ of $1.8 \mathrm{~N}$ $\mathrm{NaOH}$ to increase the absorbance at $420-450 \mathrm{~nm}$. The absorbance at $440 \mathrm{~nm}$ was measured using a UV-Vis-NIR spectrophotometer (V-670: Jasco). Control assay was done without enzyme and used as a blank. A unit of enzymatic activity (U) was defined 
as the amount of enzyme that degrades $1 \mathrm{mg}$ of substrate in $1 \mathrm{~min}$. See ESI $\uparrow$ for details on protein activity after exposure to different conditions.

\section{Acknowledgements}

The authors acknowledge financial support from MCIN/AEI/10.13039/501100011033 (grant PID2020-119748GA-I00 and CEX2019-000919-M), Generalitat Valenciana GentT Program (SEJI/2020/036) and "la Caixa" Foundation (LCF/BQ/PI19/11690022). M. G.-M. acknowledges the Spanish MICINN for a Ramón y Cajal Contract (RYC2019-027902-I).

References

[1] K. M. Koeller, C. H. Wong, Nature 2001, 409, 232.

[2] H. E. Schoemaker, D. L. Mink, M. G. WubboLts, Science (80-. ). 2003, 299, 1694.

[3] A. I. Kallenberg, F. Van Rantwijk, R. A. Sheldon, Adv. Synth. Catal. 2005, 347, 905.

[4] B. J. Li, H. Wang, T. Gong, J. J. Chen, T. J. Chen, J. L. Yang, P. Zhu, Nat. Commun. 2017, 8,1 .

[5] B. Zhang, Y. Weng, H. Xu, Z. Mao, Appl. Microbiol. Biotechnol. 2012, 93, 61.

[6] D. O. Demirkol, H. B. Yildiz, S. Sayin, M. Yilmaz, RSC Adv. 2014, 4, 19900.

[7] G. S. Wilson, Y. Hu, Chem. Rev. 2000, 100, 2693.

[8] S. A. S. Chatha, M. Asgher, H. M. N. Iqbal, Environ. Sci. Pollut. Res. 2017, 24, 14005.

[9] J. Wang, J. Lozier, G. Johnson, S. Kirshner, D. Verthelyi, A. Pariser, E. Shores, A. Rosenberg, Nat. Biotechnol. 2008, 26, 901.

[10] R. Di Cosimo, J. Mc Auliffe, A. J. Poulose, G. Bohlmann, Chem. Soc. Rev. 2013, 42, 6437.

[11] S. Averick, R. A. Mehl, S. R. Das, K. Matyjaszewski, J. Control. Release 2015, 205, 45.

[12] J. Milton Harris, R. B. Chess, Nat. Rev. Drug Discov. 2003, 2, 214.

[13] K. Ramani, S. Karthikeyan, R. Boopathy, L. J. Kennedy, A. B. Mandal, G. Sekaran, Process Biochem. 2012, 47, 435.

[14] Q. Chen, H. Schönherr, G. J. Vancso, Small 2009, 5, 1436.

[15] S. Matoori, J. C. Leroux, Mater. Horizons 2020, 7, 1297.

[16] D. Avnir, O. Lev, J. Livage, J. Mater. Chem. 2006, 16, 1013.

[17] H. H. P. Yiu, P. A. Wright, J. Mater. Chem. 2005, 15, 3690.

[18] V. Lykourinou, Y. Chen, X. Sen Wang, L. Meng, T. Hoang, L. J. Ming, R. L. 
Musselman, S. Ma, J. Am. Chem. Soc. 2011, 133, 10382.

[19] Y. Chen, V. Lykourinou, C. Vetromile, T. Hoang, L. J. Ming, R. W. Larsen, S. Ma, J. Am. Chem. Soc. 2012, 134, 13188.

[20] F. Lyu, Y. Zhang, R. N. Zare, J. Ge, Z. Liu, Nano Lett. 2014, 14, 5761.

[21] K. Liang, R. Ricco, C. M. Doherty, M. J. Styles, S. Bell, N. Kirby, S. Mudie, D. Haylock, A. J. Hill, C. J. Doonan, P. Falcaro, Nat. Commun. 2015, 6, 4.

[22] H. C. J. Zhou, S. Kitagawa, Chem. Soc. Rev. 2014, 43, 5415.

[23] O. M. Yaghi, M. O'Keeffe, N. W. Ockwig, H. K. Chae, M. Eddaoudi, J. Kim, Nature 2003, 423, 705 .

[24] B. F. Hoskins, R. Robson, J. Am. Chem. Soc. 1989, 111, 5962.

[25] F. Hiroyasu, C. K. E, O. Michael, Y. O. M, Science (80-. ). 2013, 341, 1230444.

[26] S. Ma, H. C. Zhou, Chem. Commun. 2010, 46, 44.

[27] Q. Qian, P. A. Asinger, M. J. Lee, G. Han, K. Mizrahi Rodriguez, S. Lin, F. M. Benedetti, A. X. Wu, W. S. Chi, Z. P. Smith, Chem. Rev. 2020, 120, 8161.

[28] R. B. Lin, S. Xiang, W. Zhou, B. Chen, Chem 2020, 6, 337.

[29] V. Pascanu, G. González Miera, A. K. Inge, B. Martín-Matute, J. Am. Chem. Soc. 2019, 141, 7223.

[30] G. Mínguez Espallargas, E. Coronado, Chem. Soc. Rev. 2018, 47, 533.

[31] H. Furukawa, F. Gándara, Y. B. Zhang, J. Jiang, W. L. Queen, M. R. Hudson, O. M. Yaghi, J. Am. Chem. Soc. 2014, 136, 4369.

[32] M. Mon, R. Bruno, J. Ferrando-Soria, D. Armentano, E. Pardo, J. Mater. Chem. A 2018, 6, 4912 .

[33] X. G. Wang, Z. Y. Dong, H. Cheng, S. S. Wan, W. H. Chen, M. Z. Zou, J. W. Huo, H. X. Deng, X. Z. Zhang, Nanoscale 2015, 7, 16061.

[34] T. Hidalgo, C. Serre, P. Horcajada, M. Giménez-Marqués, 2016, 307, 342.

[35] C. He, K. Lu, D. Liu, W. Lin, J. Am. Chem. Soc. 2014, 136, 5181.

[36] T. Simon-Yarza, A. Mielcarek, P. Couvreur, C. Serre, Adv. Mater. 2018, 30, 1707365.

[37] W. Liang, P. Wied, F. Carraro, C. J. Sumby, B. Nidetzky, C. K. Tsung, P. Falcaro, C. J. Doonan, Chem. Rev. 2021, 121, 1077.

[38] M. de J. Velásquez-Hernández, M. Linares-Moreau, E. Astria, F. Carraro, M. Z. Alyami, N. M. Khashab, C. J. Sumby, C. J. Doonan, P. Falcaro, Coord. Chem. Rev. 2021, 429, 213651.

[39] W. Ma, Q. Jiang, P. Yu, L. Yang, L. Mao, Anal. Chem. 2013, 85, 7550.

[40] Y. Cao, Z. Wu, T. Wang, Y. Xiao, Q. Huo, Y. Liu, Dalt. Trans. 2016, 45, 6998. 
[41] S. L. Cao, D. M. Yue, X. H. Li, T. J. Smith, N. Li, M. H. Zong, H. Wu, Y. Z. Ma, W. Y. Lou, ACS Sustain. Chem. Eng. 2016, 4, 3586.

[42] E. Gkaniatsou, C. Sicard, R. Ricoux, L. Benahmed, F. Bourdreux, Q. Zhang, C. Serre, J. P. Mahy, N. Steunou, Angew. Chemie - Int. Ed. 2018, 57, 16141.

[43] K. Liang, C. J. Coghlan, S. G. Bell, C. Doonan, P. Falcaro, Chem. Commun. 2016, 52, 473.

[44] X. Lian, Y. Fang, E. Joseph, Q. Wang, J. Li, S. Banerjee, C. Lollar, X. Wang, H. C. Zhou, Chem. Soc. Rev. 2017, 46, 3386.

[45] W. H. Chen, M. Vázquez-González, A. Zoabi, R. Abu-Reziq, I. Willner, Nat. Catal. 2018, $1,689$.

[46] S. K. Alsaiari, S. Patil, M. Alyami, K. O. Alamoudi, F. A. Aleisa, J. S. Merzaban, M. Li, N. M. Khashab, J. Am. Chem. Soc. 2018, 140, 143.

[47] N. K. Maddigan, A. Tarzia, D. M. Huang, C. J. Sumby, S. G. Bell, P. Falcaro, C. J. Doonan, Chem. Sci. 2018, 9, 4217.

[48] G. Chen, X. Kou, S. Huang, L. Tong, Y. Shen, W. Zhu, F. Zhu, G. Ouyang, Angew. Chemie - Int. Ed. 2020, 59, 2867.

[49] G. Chen, S. Huang, X. Kou, S. Wei, S. Huang, S. Jiang, J. Shen, F. Zhu, G. Ouyang, Angew. Chemie - Int. Ed. 2019, 58, 1463.

[50] T. Devic, C. Serre, Chem. Soc. Rev. 2014, 43, 6097.

[51] S. Yuan, L. Feng, K. Wang, J. Pang, M. Bosch, C. Lollar, Y. Sun, J. Qin, X. Yang, P. Zhang, Q. Wang, L. Zou, Y. Zhang, L. Zhang, Y. Fang, J. Li, H. C. Zhou, Adv. Mater. 2018, 30, 1 .

[52] P. Horcajada, S. Surblé, C. Serre, D. Y. Hong, Y. K. Seo, J. S. Chang, J. M. Grenèche, I. Margiolaki, G. Férey, Chem. Commun. 2007, 27, 2820.

[53] B. Jachimska, M. Wasilewska, Z. Adamczyk, Langmuir 2008, 24, 6867.

[54] K. Shimura, W. Zhi, H. Matsumoto, K. I. Kasai, Anal. Chem. 2000, 72, 4747.

[55] M. Ottesen, I. Svendsen, Methods Enzymol. 1970, 19, 199.

[56] G. P. Harper, R. W. Glanville, H. Thoenen, J. Biol. Chem. 1982, 257, 8541.

[57] F. Tan, M. Liu, K. Li, Y. Wang, J. Wang, X. Guo, G. Zhang, C. Song, Chem. Eng. J. 2015, 281, 360 .

[58] D. Bara, C. Wilson, M. Mörtel, M. M. Khusniyarov, S. Ling, B. Slater, S. Sproules, R. S. Forgan, J. Am. Chem. Soc. 2020, 141, 8346.

[59] K. Guesh, C. A. D. Caiuby, Á. Mayoral, M. Díaz-García, I. Díaz, M. Sanchez-Sanchez, Cryst. Growth Des. 2017, 17, 1806. 
[60] K. S. W. Sing, D. H. Everett, R. A. W. Haul, L. Moscou, R. A. Pierotti, J. Rouquerol, T. Siemieniewska, Pure Appl. Chem. 1985, 57, 603.

[61] S. Brunauer, P. H. Emmett, E. Teller, J. Am.Chem.Soc. 1938, 60, 309.

[62] M. A. Simon, E. Anggraeni, F. E. Soetaredjo, S. P. Santoso, W. Irawaty, T. C. Thanh, S. B. Hartono, M. Yuliana, S. Ismadji, Sci. Rep. 2019, 9, 1.

[63] N. K. Maddigan, A. Tarzia, D. M. Huang, C. J. Sumby, S. G. Bell, P. Falcaro, C. J. Doonan, Chem. Sci. 2018, 9, 4217.

[64] W. Liang, R. Ricco, N. K. Maddigan, R. P. Dickinson, H. Xu, Q. Li, C. J. Sumby, S. G. Bell, P. Falcaro, C. J. Doonan, Chem. Mater. 2018, 30, 1069.

[65] J. Schubert, C. Radeke, A. Fery, M. Chanana, Phys. Chem. Chem. Phys. 2019, 21, 11011.

[66] F. Roosen-Runge, B. S. Heck, F. Zhang, O. Kohlbacher, F. Schreiber, J. Phys. Chem. B 2013, 117, 5777.

[67] S. Kumar, I. Yadav, D. Ray, S. Abbas, D. Saha, V. K. Aswal, J. Kohlbrecher, Biomacromolecules 2019, 20, 2123.

[68] X. Li, L. Lachmanski, S. Safi, S. Sene, C. Serre, J. M. Grenèche, J. Zhang, R. Gref, Sci. Rep. 2017, 7, 1.

[69] I. Lee, A. R. Salomon, K. Yu, J. W. Doan, L. I. Grossman, M. Hüttemann, Biochemistry 2006, 45, 9121.

[70] A. Lundby, A. Secher, K. Lage, N. B. Nordsborg, A. Dmytriyev, C. Lundby, J. V. Olsen, Nat. Commun. 2012, 3, 810.

[71] V. Agostoni, T. Chalati, P. Horcajada, H. Willaime, R. Anand, N. Semiramoth, T. Baati, S. Hall, G. Maurin, H. Chacun, K. Bouchemal, C. Martineau, F. Taulelle, P. Couvreur, C. Rogez-Kreuz, P. Clayette, S. Monti, C. Serre, R. Gref, Adv. Healthc. Mater. 2013, 2, 1630.

[72] E. Bellido, M. Guillevic, T. Hidalgo, M. J. Santander-Ortega, C. Serre, P. Horcajada, Langmuir 2014, 30, 5911.

[73] N. Genov, B. Filippi, P. Dolashka, K. S. Wilson, C. Betzel, Int. J. Pept. Protein Res. 1995, 45,391 .

[74] J. A. Wells, D. A. Estell, Trends Biochem. Sci. 1988, 13, 291.

[75] S. Arana-Peña, N. S. Rios, D. Carballares, C. Mendez-Sanchez, Y. Lokha, L. R. B. Gonçalves, R. Fernandez-Lafuente, Front. Bioeng. Biotechnol. 2020, 8, 36.

[76] D. H. Zhang, L. X. Yuwen, C. Li, Y. Q. Li, Bioresour. Technol. 2012, 124, 233.

[77] E. Jurrus, D. Engel, K. Star, K. Monson, J. Brandi, L. E. Felberg, D. H. Brookes, L. 
Wilson, J. Chen, K. Liles, M. Chun, P. Li, D. W. Gohara, T. Dolinsky, R. Konecny, D. R. Koes, J. E. Nielsen, T. Head-Gordon, W. Geng, R. Krasny, G. W. Wei, M. J. Holst, J. A. McCammon, N. A. Baker, Protein Sci. 2018, 27, 112.

[78] N. Mirkin, J. Jaconcic, V. Stojanoff, A. Moreno, Proteins Struct. Funct. Genet. 2008, $70,83$.

[79] T. Prangé, M. Schiltz, L. Pernot, N. Colloc', S. Longhi, W. Bourguet, R. Fourme, Proteins 1998, 30, 61.

[80] R. Maurus, R. Bogumil, N. T. Nguyen, A. G. Mauk, G. Brayer, Biochem. J. 1998, 332, 67.

[81] K. A. Majorek, P. J. Porebski, A. Dayal, M. D. Zimmerman, K. Jablonska, A. J. Stewart, M. Chruszcz, W. Minor, Mol. Immunol. 2012, 52, 174.

[82] J. C. P. Broekhoff, J. H. de Boer, J. Catal. 1967, 9, 8.

[83] J. C. P. Broekhoff, J. H. de Boer, J. Catal. 1968, 10, 377.

[84] M. Jaroniec, M. Kruk, C. P. Jaroniec, A. Sayari, Adsorption 1999, 5, 39.

[85] J. Charney, R. M. Tomarelli, J. Biol. Chem. 1947, 171, 501. 
